Products and Services In Practice is provided to readers using text and images from the manufacturer, supplier or distributor and does not imply endorsement by $B D J$ In Practice. Normal and prudent research should be exercised before purchase or use of any product mentioned.

Please send product and services news through to David Westgarth, BDJ In Practice via: David.Westgarth@bda.org

\section{Two new models launched}

Renowned around the world for industryleading oral health solutions, Waterpik is delighted to bring you two brand-new models.

The Waterpik Ultra Plus Water Flosser features 10 pressure settings, a highvolume reservoir for $90+$ seconds of use and in-lid storage to keep the 6 tips it comes with clean and tidy.

For patients who need a more compact and cordless design, the Waterpik Cordless Select Water Flosser features a 4-hour rapid charge, 2 pressure settings, 45 -second water capacity and 4 tips.

To help your patients enhance their homecare oral health routines, discover the clinically proven solutions from Waterpik. Lunch \& Learn sessions with our Professional Educators are available virtually or in-person (wherever permitted and safe to do so).

For more information on Waterpik products visit www.waterpik.co.uk.
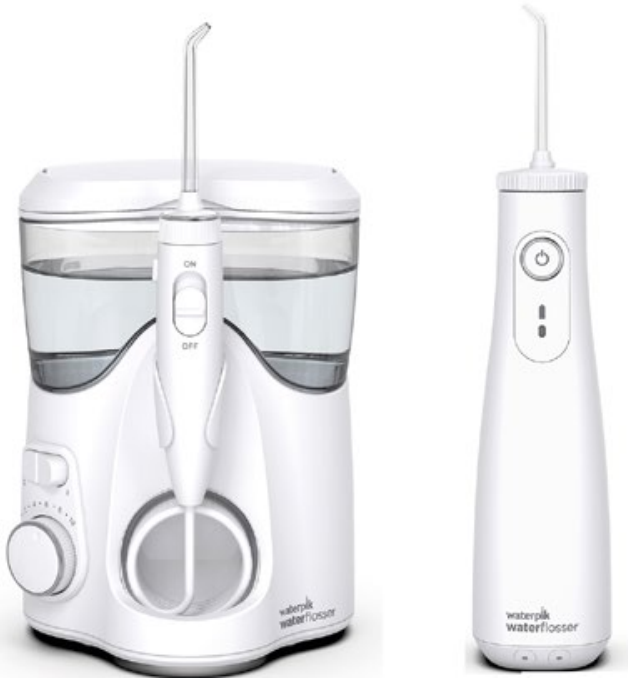

\title{
Convenient for all
}

Image acquisition needs to be swift, accurate and convenient.

Don't settle for less than the CS 8100 3D

Evo Edition CBCT system from Carestream Dental.

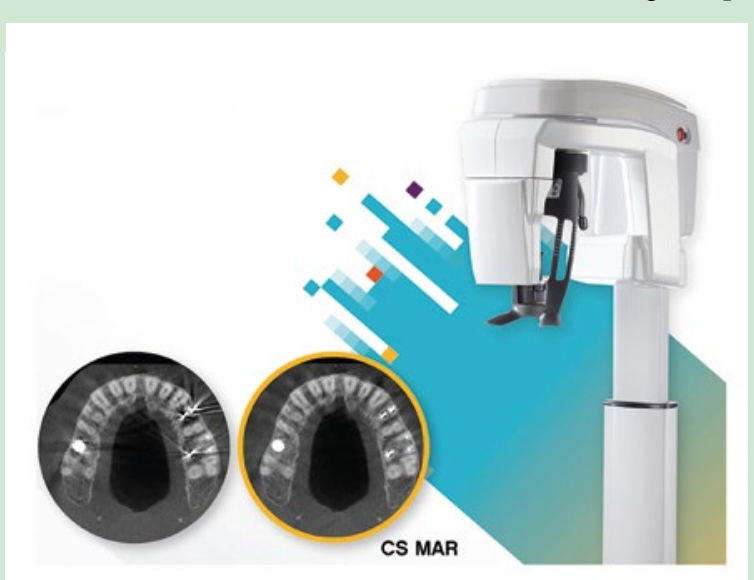

Its innovative Tomosharp technology and advanced image processing capabilities ensure exceptional image sharpness, whilst the open, face-to-face design helps encourage increased patient comfort.

Couple these features with ultra-fast scanning times (7 seconds) and the unit's compact size and ergonomic functionality, and you can see why the CS $81003 \mathrm{D}$ Evo Edition is a convenient choice for practitioners and patients alike.

For more information, contact Carestream Dental on 08001699692 or visit www.carestreamdental.co.uk

\section{Not a chore but a passion}

At Colosseum Dental, we stand by four key values:

$\rightarrow$ Care

$\rightarrow$ Entrepreneurship

$\rightarrow$ Passion

$\rightarrow$ Collaboration

We are passionate about everything we do at Colosseum Dental. We want to be the best dental provider we can be and we know this will require hard work, enthusiasm and drive.

That's why we are proud to work with so many passionate professionals in practices and throughout our support teams. We want to energise, engage and inspire people to fulfil their potential and help us deliver the highest quality of patient care.

Are you passionate about clinical excellence and about doing things differently for the benefit of patients and the profession? You'll fit right in at Colosseum Dental.

For more information about Colosseum Dental visit www.colosseumdental.co.uk.
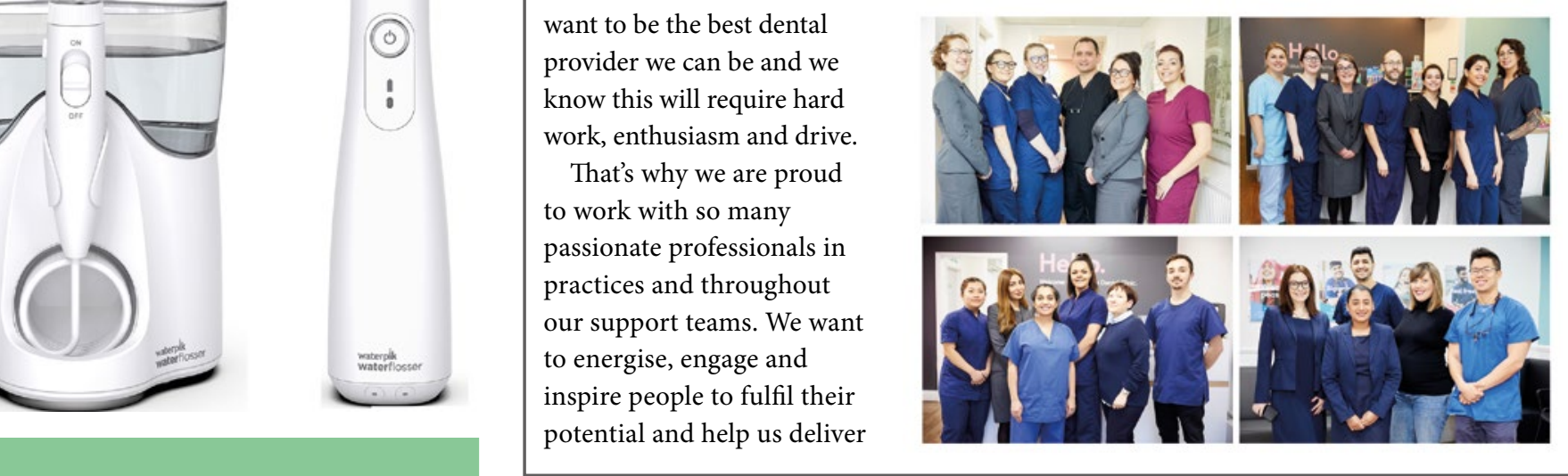